\title{
Anionic Polymerization of Novel Styrene Derivatives Bearing Various Amino Groups at ortho-Position
}

\author{
Hiroharu AJIRO, Shigeki HABAue, ${ }^{*}$ and Yoshio OKAмото ${ }^{\dagger}$
}

\begin{abstract}
Department of Applied Chemistry, Graduate School of Engineering, Nagoya University, Chikusa-ku, Nagoya 464-8603, Japan ${ }^{*}$ Department of Chemistry \& Chemical Engineering, Faculty of Engineering, Yamagata University, Yonezawa 992-8510, Japan
\end{abstract}

(Received November 10, 2003; Accepted January 27, 2004)

\begin{abstract}
The novel styrene derivatives bearing various amino groups at ortho-position, 2-(1-indolinyl)methylstyrene (2), 2-(9-carbazolyl)methylstyrene (3), 2-(N,N-diphenylamino)methylstyrene (4), 2-(N-3-methoxyphenyl- $N$ phenylamino)methylstyrene (5), and 2-( $N$-3-methylphenyl- $N$-phenylamino)methylstyrene (6), were synthesized and polymerized with radical and anionic initiations. As the bulkiness of the substituents at the ortho-position increased, the polymerizabilities of these monomers during the radical and anionic methods significantly decreased. The anionic polymerization of 4-6 with the $n$-butyllithium (-)-sparteine complex in toluene at $0{ }^{\circ} \mathrm{C}$ afforded the optically active polymers $\left([\alpha]^{25}{ }_{365}+48^{\circ}\right.$ to $\left.+22^{\circ}\right)$, whereas no optical activity was observed for the polymers of $\mathbf{2}$ and $\mathbf{3}$ obtained under the same conditions. The optically active polymers likely have a chiral helical conformation which is related to a high stereoregularity.

KEY WORDS 2-(Aminomethyl)styrene / Anionic Polymerization / Stereoregularity / Optically Active Polymer /
\end{abstract}

In the syntheses of vinyl polymers, the substituents on the monomers are very important for not only introducing functionality but also controlling the reactivities of the monomers and stereostructures during the polymerization. The ortho-substituents on the styrene derivatives significantly influence both the polymerizability and the structure of the obtained polymers due to the position very close to the growing chain end during the polymerization. Some ortho-substituted styrene derivatives have been reported. ${ }^{1}$ For example, Natta et al. reported the polymerizabilities of various styrene derivatives substituted at the ortho-, meta-, and para-positions by methyl or other groups. ${ }^{2}$ The anionic polymerization of ortho- and para-methoxystyrenes was studied by Geerts et al., clarifying the fact that the favorably located at the ortho-methoxy group of a terminal unit induces the instantaneous initiation reaction, while the initiation of para-methoxystyrene was slow. ${ }^{3}$ Yuki et al. also investigated the stereospecific anionic polymerization of ortho-methoxystyrene. ${ }^{4}$

The proper bulky substituent on the side chain may play an important role in the formation of a higher order structure. Poly(triphenylmethyl methacrylate) with a high isotacticity, for example, can maintain the helical structure by the bulky triphenylmethyl groups, which is stable even in solution. ${ }^{5}$ On the other hand, it is well known that isotactic polystyrene has a $3_{1}$ helical conformation in a crystalline or gel state. ${ }^{2}$ However, few studies have been reported concerning the polystyrene derivatives with a stable helical con- formation in solution. Ortiz and Khan reported that the optically active poly(3-methyl-4-vinylpyridine) was prepared using chiral lithium amide derivatives as an anionic initiator, ${ }^{6}$ but the specific rotation slowly disappeared at room temperature in solution.

Recently, we reported that the anionic polymerization of a styrene derivative (1) bearing the optically active diamine at ortho-position produced a polymer with a high stereoregularity and a stable regular conformation based on the stereoregular backbone structure. ${ }^{7}$ The amino group at the ortho-position appears to coordinate to the counter cation and control the stereochemistry during the polymerization.

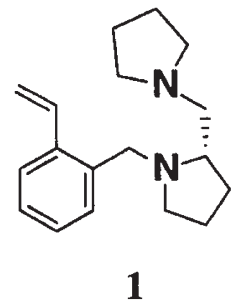

In the present study, we synthesized the novel styrene derivatives bearing achiral and bulky amino groups at the ortho-position, 2-(1-indolinyl)methylstyrene (2), 2-(9-carbazolyl)methylstyrene (3), 2( $N, N$-diphenylamino)methylstyrene (4), 2-( $N$-3-methoxyphenyl- $N$-phenylamino)methylstyrene (5), and 2-( $N$-3-methylphenyl- $N$-phenylamino)methylstyrene (6), and investigated the effect of the ortho-substituents on the polymerizabilities and stereocontrol during the radical and anionic polymerizations. The chiropti-

${ }^{\dagger}$ To whom correspondence should be addressed (E-mail: okamoto@apchem.nagoya-u.ac.jp). 
cal properties of the polymers obtained by the asymmetric anionic polymerization with the chiral complex of $n$-butyllithium ( $n$-BuLi) and (-)-sparteine ((-)-Sp) were also discussed.

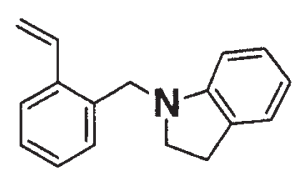

2<smiles>[R]c1cccc(N(Cc2ccccc2C=C)c2ccccc2)c1</smiles>

\section{EXPERIMENTAL}

\section{Materials}

$\alpha, \alpha^{\prime}$-Azobisisobutyronitrile (AIBN) was purified by recrystallization from methanol. (-)-Sp and 2,3-dimethoxy-1,4-bis(dimethylamino)butane $((-)-$ and $(+)-$ DDB) were purified by distillation. Toluene used for the polymerization was distilled from $\mathrm{Na}$ wire, and distilled again from $n$-BuLi under high vacuum just before use. $n$-BuLi was prepared from 1-chlorobutane and lithium powder in heptane under an atmosphere of argon.

\section{Syntheses of Monomers 2-6}

Monomers 2-6 were synthesized from ortho-chloromethylstyrene and the corresponding amines using $\mathrm{NaH}$ in a mixture of THF and DMF at r.t. or $40^{\circ} \mathrm{C}$. The obtained 2-6 were purified by column chromatography $\left(\mathrm{SiO}_{2}\right.$, hexane/ethyl acetate $\left.=5 / 1\right)$ for $\mathbf{2}$, $\mathbf{5}$, and $\mathbf{6}$, or recrystallization for $\mathbf{3}$ and $\mathbf{4}$.

2-(1-Indolinyl)methylstyrene (2): $\quad$ Yield $91 \%$. ${ }^{1} \mathrm{HNMR}\left(400 \mathrm{MHz}, \mathrm{CDCl}_{3}, \delta, \mathrm{ppm}\right): 2.94(\mathrm{t}, 2 \mathrm{H}$, $\left.J=8.4 \mathrm{~Hz}, \quad \mathrm{ArCH}_{2}\right), \quad 3.25 \quad(\mathrm{t}, \quad 2 \mathrm{H}, \quad J=8.4 \mathrm{~Hz}$, $\mathrm{CH}_{2} \mathrm{NAr}$ ), 4.25 (s, $\left.2 \mathrm{H}, \mathrm{NCH}_{2} \mathrm{Ar}\right), 5.30(\mathrm{dd}, 1 \mathrm{H}$, $J=1.6$ and $\left.11.2 \mathrm{~Hz},=\mathrm{CH}_{2}\right), 5.67(\mathrm{dd}, 1 \mathrm{H}, J=1.6$ and $\left.17.4 \mathrm{~Hz},=\mathrm{CH}_{2}\right), 6.53(\mathrm{~d}, 1 \mathrm{H}, J=8.0 \mathrm{~Hz}, \mathrm{Ar})$, 7.05-7.55 (m, 9H, Ar and =CH). IR (neat, $\left.\mathrm{cm}^{-1}\right)$ 2822, 1606, 1488, 1268, 915, 771, 746. MS (FAB) $m / z 235\left([\mathrm{M}]^{+}\right)$.

2-(9-Carbazolyl)methylstyrene (3): $\quad$ Yield 56\%. Recrystallized from hexane/diethyl ether $=4 / 1 ; \mathrm{mp}$ 126.4-126.9 ${ }^{\circ} \mathrm{C} . \quad{ }^{1} \mathrm{HNMR} \quad\left(400 \mathrm{MHz}, \mathrm{CDCl}_{3}, \quad \delta\right.$, ppm): $5.46\left(\mathrm{dd}, 1 \mathrm{H}, J=1.2\right.$ and $\left.7.2 \mathrm{~Hz},=\mathrm{CH}_{2}\right)$, $5.55\left(\mathrm{~s}, 2 \mathrm{H}, \mathrm{ArCH}_{2} \mathrm{~N}\right), 5.76(\mathrm{dd}, 1 \mathrm{H}, J=1.2$ and $\left.17.4 \mathrm{~Hz},=\mathrm{CH}_{2}\right), 6.50(\mathrm{~d}, 1 \mathrm{H}, J=8.0 \mathrm{~Hz}, \mathrm{Ar}), 6.98$ (m, 1H, Ar), 7.12-7.55 (m, 10H, Ar and $=\mathrm{CH}), 8.14$ (m, 2H, Ar). IR (KBr, cm $\left.{ }^{-1}\right) 3054,1626,1598$, $1485,1326,750,722$. MS (FAB) $m / z 284\left([\mathrm{M}+\mathrm{H}]^{+}\right)$.

2-(N,N-Diphenylamino)methylstyrene (4): Yield $51 \%$. Recrystallized from hexane $/$ chloroform $=30 / 1$; mp 104.3-105.1 ${ }^{\circ} \mathrm{C} .{ }^{1} \mathrm{HNMR}\left(400 \mathrm{MHz}, \mathrm{CDCl}_{3}, \delta\right.$, ppm): $5.01\left(\mathrm{~s}, 2 \mathrm{H}, \mathrm{ArCH}_{2} \mathrm{~N}\right), 5.34(\mathrm{dd}, 1 \mathrm{H}, J=1.6$ and $\left.11.0 \mathrm{~Hz},=\mathrm{CH}_{2}\right), 5.65(\mathrm{dd}, 1 \mathrm{H}, J=1.6$ and $\left.17.2 \mathrm{~Hz},=\mathrm{CH}_{2}\right), 6.91-7.24(\mathrm{~m}, 13 \mathrm{H}, \mathrm{Ar}$ and $=\mathrm{CH})$, $7.38(\mathrm{~m}, 1 \mathrm{H}, \mathrm{Ar}), 7.47(\mathrm{~m}, 1 \mathrm{H}, \mathrm{Ar})$. IR $\left(\mathrm{KBr}, \mathrm{cm}^{-1}\right)$ 3066, 1586, 1495, 1229, 747, 726, 696. MS (FAB) $m / z 286\left([\mathrm{M}+\mathrm{H}]^{+}\right)$.

2-(N-3-Methoxyphenyl-N-phenylamino)methylstyrene (5): Yield 75\%. ${ }^{1} \mathrm{HNMR}\left(400 \mathrm{MHz}, \mathrm{CDCl}_{3}, \delta\right.$, ppm): 3.69 (s, $\left.3 \mathrm{H}, \mathrm{CH}_{3} \mathrm{O}\right), 5.00\left(\mathrm{~s}, 2 \mathrm{H}, \mathrm{ArCH}_{2} \mathrm{~N}\right), 5.33$ $\left(\mathrm{dd}, 1 \mathrm{H}, J=1.6\right.$ and $\left.11.0 \mathrm{~Hz},=\mathrm{CH}_{2}\right), 5.64(\mathrm{dd}, 1 \mathrm{H}$, $J=1.6$ and $\left.17.2 \mathrm{~Hz},=\mathrm{CH}_{2}\right), 6.46(\mathrm{~m}, 1 \mathrm{H}, \mathrm{Ar}), 6.57$ $(\mathrm{m}, 2 \mathrm{H}, \mathrm{Ar}), 6.91-7.25(\mathrm{~m}, 9 \mathrm{H}, \mathrm{Ar}$ and $=\mathrm{CH}), 7.38$ $(\mathrm{m}, 1 \mathrm{H}, \operatorname{Ar}), 7.46(\mathrm{~m}, 1 \mathrm{H}, \mathrm{Ar})$. IR (neat, $\left.\mathrm{cm}^{-1}\right)$ 3025, 1591, 1494, 1165, 1077, 754, 693. MS (FAB) $m / z 316\left([\mathrm{M}+\mathrm{H}]^{+}\right)$.

2-(N-3-Methylphenyl-N-phenylamino)methylstyrene (6): Yield 60\%. ${ }^{1} \mathrm{HNMR}\left(400 \mathrm{MHz}, \mathrm{CDCl}_{3}, \delta, \mathrm{ppm}\right)$ : $2.24\left(\mathrm{~s}, 3 \mathrm{H}, \mathrm{CH}_{3}\right), 5.00\left(\mathrm{~s}, 2 \mathrm{H}, \mathrm{ArCH}_{2} \mathrm{~N}\right), 5.31(\mathrm{dd}$, $1 \mathrm{H}, J=1.2$ and $\left.11.0 \mathrm{~Hz},=\mathrm{CH}_{2}\right), 5.63(\mathrm{dd}, 1 \mathrm{H}$, $J=1.2$ and $\left.17.4 \mathrm{~Hz},=\mathrm{CH}_{2}\right), 6.74-7.19(\mathrm{~m}, 12 \mathrm{H}, \mathrm{Ar}$ and $=\mathrm{CH}), 7.39(\mathrm{~m}, 1 \mathrm{H}, \mathrm{Ar}), 7.45(\mathrm{~m}, 1 \mathrm{H}, \mathrm{Ar})$. IR (neat, $\mathrm{cm}^{-1}$ ) 3060, 1595, 1496, 1454, 1264, 1239, 770. MS (FAB) $m / z 300\left([\mathrm{M}+\mathrm{H}]^{+}\right)$.

\section{Polymerization}

Anionic polymerization was carried out in a glass ampule equipped with a three-way stopcock. The polymerization was initiated by adding a heptane solution of $n$-BuLi or a mixture of $n$-BuLi solution and a chiral diamine (1:1.2) to a monomer solution (1.0 M, 1.6-2.0 mmol) under dry nitrogen, and was later terminated with a small amount of methanol. The polymers were precipitated in a large amount of methanol, then separated by centrifugation, and dried in vacuo.

\section{Measurements}

The ${ }^{1} \mathrm{H}$ and ${ }^{13} \mathrm{C}$ NMR spectra were measured using a Varian Gemini-2000 (400 MHz for $\left.{ }^{1} \mathrm{H}\right)$ or UNITYINOVA-500 $\left(500 \mathrm{MHz}\right.$ for $\left.{ }^{1} \mathrm{H}\right)$ spectrometer in $\mathrm{CDCl}_{3}$. Infrared (IR) spectra were recorded on a JASCO FT/IR-620 spectrometer. Mass spectra were taken on a JEOL LMS-AX505HA mass spectrometer. Optical rotation was measured using a JASCO P-1010 or JASCO P-1030 polarimeter at $25^{\circ} \mathrm{C}$. The UV spectra were measured on a JASCO Ubest-55 spectrophotometer. The Circular dichroism (CD) spectra were obtained using a JASCO J-720L apparatus. The molecular weight of the polymer was determined by a vapor pressure osmometer (VPO, Gonotec Osmomat 070) 
and size-exclusion chromatographic analysis (SEC) using a Shodex System-21 SEC system equipped with Shodex UV-41, Shodex RI-71S, JASCO OR-990 polarimeteric detector, and a Wyatt Technology DAWN DSP-F multiangle light scattering (LS) detector at $40^{\circ} \mathrm{C}$. Two commercial columns (Shodex KF-803 and KF-806L) were connected in series, and tetrahydrofuran (THF) was used as the eluent.

\section{RESULTS AND DISCUSSION}

The radical polymerization of 2-6 with $\alpha, \alpha^{\prime}$-azobisisobutyronitrile (AIBN) in toluene at $60^{\circ} \mathrm{C}$ was performed, and the results are listed in Table I together

Table I. Radical Polymerization of $\mathbf{2 - 8}$ with AIBN ${ }^{\mathrm{a}}$

\begin{tabular}{|c|c|c|c|c|c|c|}
\hline \multirow{2}{*}{ Entry } & \multirow{2}{*}{ Monomer } & Conc. & Time & Yield $^{\mathrm{b}}$ & $M_{\mathrm{n}}^{\mathrm{c}}$ & $M_{\mathrm{w}}{ }^{\mathrm{c}}$ \\
\hline & & $\overline{\mathrm{mol} / \mathrm{L}}$ & $\mathrm{h}$ & $\%$ & $\times 10^{3}$ & $M_{\mathrm{n}}$ \\
\hline $1^{\mathrm{d}}$ & 7 & $-^{\mathrm{e}}$ & 24 & 59 & 26 & 1.9 \\
\hline $2^{\mathrm{d}}$ & 8 & $-^{\mathrm{e}}$ & 20 & 89 & $-^{\mathrm{f}}$ & $-^{\mathrm{f}}$ \\
\hline 3 & 2 & 2.2 & 20 & 78 & 28 & 2.8 \\
\hline 4 & 3 & 0.8 & 20 & 43 & 5.6 & 1.9 \\
\hline 5 & 4 & 0.8 & 20 & 9 & 2.6 & 1.1 \\
\hline 6 & 4 & 1.7 & 20 & 13 & 3.1 & 1.1 \\
\hline 7 & 5 & 1.7 & 24 & 16 & 3.3 & 1.2 \\
\hline 8 & 6 & 1.7 & 20 & 7 & 3.9 & 1.1 \\
\hline
\end{tabular}

${ }^{\text {a }}$ Solvent $=$ toluene, temp. $=60^{\circ} \mathrm{C},[$ monomer $] /[$ initiator $]=$ 40. ${ }^{\mathrm{b}} \mathrm{Hexane}$-insoluble part. ${ }^{\mathrm{c}}$ Determined by SEC in THF with RI or UV (polystyrene standard). ${ }^{\mathrm{d}} \operatorname{Ref} 7 .{ }^{\mathrm{e}} \mathrm{In}$ bulk. ${ }^{\mathrm{f}}$ The obtained polymer was insoluble in common organic solvents. with those of 2-( $N, N$-dimethylamino)methylstyrene $(7)^{7}$ and 2-(1-pyrrolidinyl)methylstyrene $(\mathbf{8})^{7}$ for comparison. The polymerization of $\mathbf{8}$ in bulk gave an insoluble polymer in common organic solvents, such as THF and $\mathrm{CHCl}_{3}$, with a good yield, although the detailed structure is unclear. The substituent at the ortho-position of styrene significantly affected the polymer yield and the number average molecular weight $\left(M_{\mathrm{n}}\right)$, and polymerizabilities clearly decreased with an increase in the bulkiness of the substituents. The monomers 4-6 possessing the diphenylaminomethyl group afforded the polymers in much lower yields (7-16\%) with an $M_{\mathrm{n}}$ value around 3000-4000.<smiles>C=Cc1ccccc1CN(C)C</smiles>

7<smiles>C=Cc1ccccc1CN1CCCC1</smiles>

8
The results of the anionic polymerization of $\mathbf{2 - 8}$ with $n$-BuLi or the complexes of $n$-BuLi with the optically active diamines (-)-Sp and (-)- or (+)-DDB in toluene are summarized in Table II. The typical red color due to a benzyl anion was observed in all cases during the polymerization. The obtained polymers were fully soluble in THF and $\mathrm{CHCl}_{3}$. As previously reported, the polymerization of $\mathbf{8}$ with $n$-BuLi in toluene at $0{ }^{\circ} \mathrm{C}$ quantitatively proceeded, although the

Table II. Anionic Polymerization of $2-\mathbf{8}^{\mathrm{a}}$

\begin{tabular}{|c|c|c|c|c|c|c|c|c|}
\hline \multirow{2}{*}{ Entry } & \multirow{2}{*}{ Monomer } & \multirow{2}{*}{ Initiator } & {$[$ Monomer] } & \multirow{2}{*}{$\begin{array}{c}\text { Temp. } \\
{ }^{\circ} \mathrm{C}\end{array}$} & \multirow{2}{*}{$\begin{array}{c}\text { Yield }^{\mathrm{b}} \\
\%\end{array}$} & \multirow{2}{*}{\begin{tabular}{|c|}
$M_{\mathrm{n}}{ }^{\mathrm{c}}$ \\
$\times 10^{3}$
\end{tabular}} & \multirow{2}{*}{$\frac{M_{\mathrm{w}}{ }^{\mathrm{c}}}{M_{\mathrm{n}}}$} & \multirow{2}{*}{$\frac{[\alpha]^{25} 365^{\mathrm{d}}}{\operatorname{deg}}$} \\
\hline & & & [Initiator] & & & & & \\
\hline $1^{\mathrm{e}}$ & 7 & $n$-BuLi & 20 & 0 & 0 & - & - & - \\
\hline $2^{\mathrm{e}}$ & 7 & $n$-BuLi & 20 & 30 & 25 & 3.5 & 1.1 & - \\
\hline $3^{\mathrm{e}}$ & 8 & $n$-BuLi & 20 & 0 & $78^{\mathrm{f}}$ & 5.0 & 1.7 & - \\
\hline 4 & 2 & $n$-BuLi & 20 & 0 & 95 & 32 & 2.1 & - \\
\hline 5 & 2 & $n$-BuLi & 20 & -78 & 0 & - & - & - \\
\hline 6 & 3 & $n$-BuLi & 20 & 0 & 41 & 4.4 & 1.4 & - \\
\hline 7 & 4 & $n$-BuLi & 20 & 0 & 26 & $4.9(6.1)^{\mathrm{g}}$ & 1.3 & - \\
\hline 8 & 5 & $n$-BuLi & 10 & 0 & 23 & 2.9 & 1.4 & - \\
\hline 9 & 6 & $n$-BuLi & 20 & 0 & 12 & 2.2 & 1.7 & - \\
\hline 10 & 2 & $n$-BuLi-(+)-DDB & 20 & 0 & 97 & 9.1 & 1.5 & $\sim 0$ \\
\hline 11 & 3 & $n$-BuLi-(-)-DDB & 20 & 0 & 78 & 7.7 & 1.5 & $\sim 0$ \\
\hline 12 & 3 & $n$-BuLi-(-)-Sp & 20 & 0 & 14 & 2.9 & 1.5 & $\sim 0$ \\
\hline 13 & 4 & $n$-BuLi-(-)-DDB & 20 & 0 & 56 & $13(32)^{\mathrm{h}}$ & 3.3 & $\sim 0$ \\
\hline 14 & 4 & $n$-BuLi-(-)-Sp & 20 & 0 & 20 & 3.6 & 1.1 & $+39^{\mathrm{i}}$ \\
\hline 15 & 5 & $n$-BuLi-(-)-Sp & 10 & 0 & 46 & 3.7 & 1.1 & +48 \\
\hline 16 & 5 & $n$-BuLi-(-)-Sp & 10 & 30 & 22 & 2.3 & 1.3 & +17 \\
\hline $17^{\mathrm{j}}$ & 5 & $n$-BuLi-(-)-Sp & 30 & 0 & 16 & 3.3 & 1.1 & +37 \\
\hline 18 & 6 & $n$-BuLi-(-)-Sp & 20 & 0 & 16 & 2.0 & 1.4 & +22 \\
\hline
\end{tabular}

${ }^{\mathrm{a}}$ Solvent $=$ toluene, time $=20 \mathrm{~h},[\mathrm{monomer}]=1.0 \mathrm{~mol} / \mathrm{L} .{ }^{\mathrm{b}} \mathrm{MeOH}$-insoluble part. ${ }^{\mathrm{c}}$ Determined by SEC with RI or UV in THF (polystyrene standard). ${ }^{\mathrm{d}} \mathrm{In} \mathrm{CHCl}_{3}, c=0.30-0.38$. ${ }^{\mathrm{e}}$ Ref $7 .{ }^{\mathrm{f}}$ Conversion $>99 \%$. ${ }^{\mathrm{g}}$ Determined by VPO. ${ }^{\mathrm{h}}$ Determined by GPC with LS. ${ }^{\mathrm{i}}[\alpha]^{25} \mathrm{D}=+10 .{ }^{\mathrm{j}}$ Time $=100 \mathrm{~h}$. 
polymerization of $\mathbf{7}$ did not afford a methanol-insoluble polymer at the same temperature (Table II, entries 1-3) probably due to the bulkiness of the ortho-substituents. ${ }^{7}$ The polymerization of $\mathbf{2}$ with $n$-BuLi at $0{ }^{\circ} \mathrm{C}$ produced to give the polymer in a good yield (entry 4), suggesting that the indolinyl group is less hindered and provides a polymer under these conditions. However, the polymerization hardly proceeded at a lower temperature (entry 5). In contrast, the bulkiness of the substituents of 3-6, significantly influenced the anionic polymerizability, which was rather similar to that of the radical polymerization shown in Table I, and the polymer yields for 3-6 were much lower than those for $\mathbf{2}$ and $\mathbf{8}$.

On the other hand, the polymerization using the $n$ BuLi- (-)- or (+)-DDB complex as an initiator afforded poly $(3)$ and poly(4) in improved yields, 78\% and $56 \%$, with a molecular weight, $M_{\mathrm{n}}=7700$ and 13000, respectively (entries 11 and 13), while these polymers showed almost no optical activity. The polymerizations of 3-6 with (-)-Sp as a chiral diamine in toluene at $0^{\circ} \mathrm{C}$ resulted in lower yields than those of the polymerization with a DDB ligand. Interestingly, poly(4), poly(5), and poly(6), bearing $N, N$-diphenylamino groups as the substituent, obtained with the $n$-BuLi-(-)-Sp system, showed a positive specific rotation $\left([\alpha]^{25}{ }_{365}+22^{\circ}\right.$ to $+48^{\circ}$, in $\mathrm{CHCl}_{3}$ ) (entries 14 , $15,17$, and 18$)$, although poly(3) had almost no optical rotatory power (entry 12). During the asymmetric polymerization of 5 with (-)-Sp at a higher temperature $\left(30^{\circ} \mathrm{C}\right)$, the specific rotation of the obtained polymer decreased to $+17^{\circ}$ (entry 16). Therefore, the polymerization conditions and the bulkiness of the ortho-substituent are very important for introducing the chirality to the polymer.

Figure 1 shows the ${ }^{1} \mathrm{HNMR}$ spectra of $\mathbf{4}$ and poly(4) obtained with $n$-BuLi (Table II, entry 7). Each peak is assigned as shown in the figures, and a broad peak pattern was observed for the polymer. Figure 2 depicts the ${ }^{13} \mathrm{CNMR}$ spectra of the monomer and the polymer of 4 . The tacticity of the polystyrene derivatives is often estimated from the spectral pattern of the C-1 (phenyl) carbon, ${ }^{8}$ whose spectra of poly(4)s, $\operatorname{poly}(\mathbf{5})$, and $\operatorname{poly}(\mathbf{6})$ obtained under various conditions by the anionic methods are shown in Figure 3. Very different spectral patterns were observed between poly(4)s obtained without and with (-)-Sp $(\mathrm{a}-\mathrm{c})$, indicating that the tacticities of these polymers are different from one another and are significantly affected by the anionic initiators. In addition, a similar spectral pattern with relatively sharp peaks was observed for the polymers prepared with the complex of $n$-BuLi and (-)-Sp (c-e). Therefore, the polymers prepared with (-)-Sp must have some stereoregular structure in the main chain, although the detailed as- (a) monomer 4

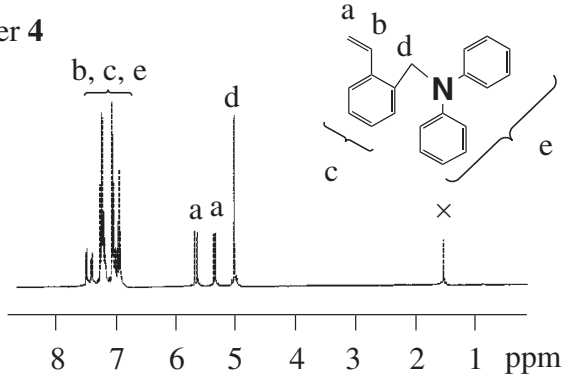

(b) $\operatorname{poly}(4)$

Aromatic

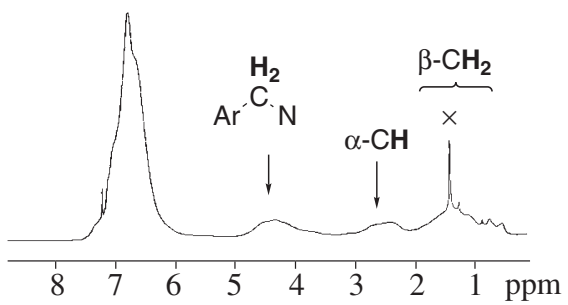

Figure 1. ${ }^{1} \mathrm{HNMR}$ spectra of $\mathbf{4}$ (in $\mathrm{CDCl}_{3}$ at room temperature, $400 \mathrm{MHz}$ ) (a) and poly(4) obtained with $n$-BuLi (in $\mathrm{CDCl}_{3}$ at $\left.60^{\circ} \mathrm{C}, 500 \mathrm{MHz}\right)(\mathrm{b})$.

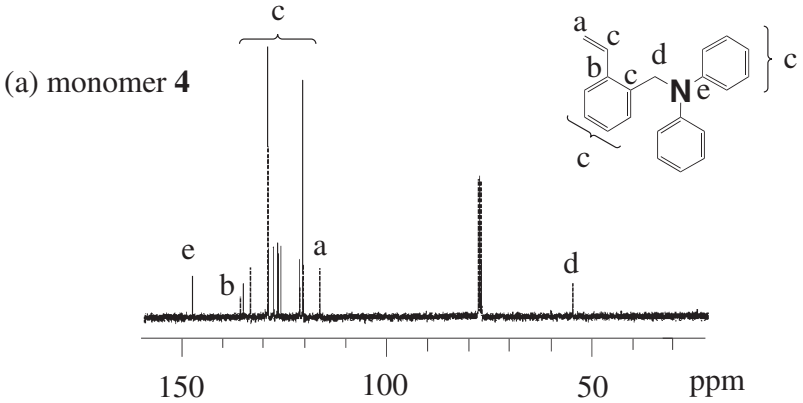

(b) $\operatorname{poly}(4)$

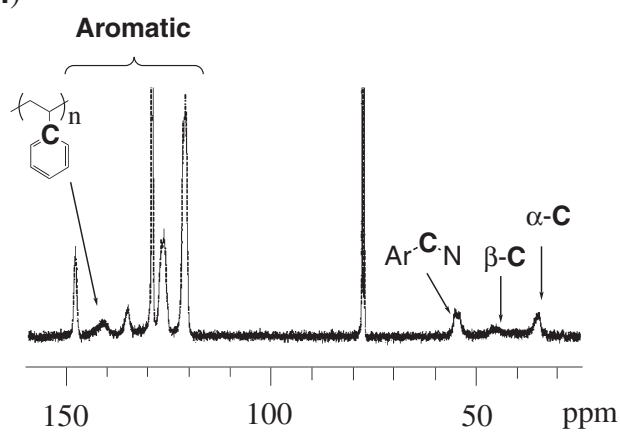

Figure 2. ${ }^{13} \mathrm{C} \mathrm{NMR}$ spectra of $\mathbf{4}$ (in $\mathrm{CDCl}_{3}$ at room temperature, $100 \mathrm{MHz}$ ) (a) and poly(4) obtained with $n$-BuLi-(-)-DDB (in $\mathrm{CDCl}_{3}$ at $60^{\circ} \mathrm{C}, 125 \mathrm{MHz}$ ) (b).

signment of the tacticities is unclear.

The SEC traces of the optically active poly(5) obtained with the (-)-Sp complex (Table II, entry 15) monitored with UV and polarimeteric detectors are shown in Figure 4. The SEC curve of $\operatorname{poly}(\mathbf{5})$ for 


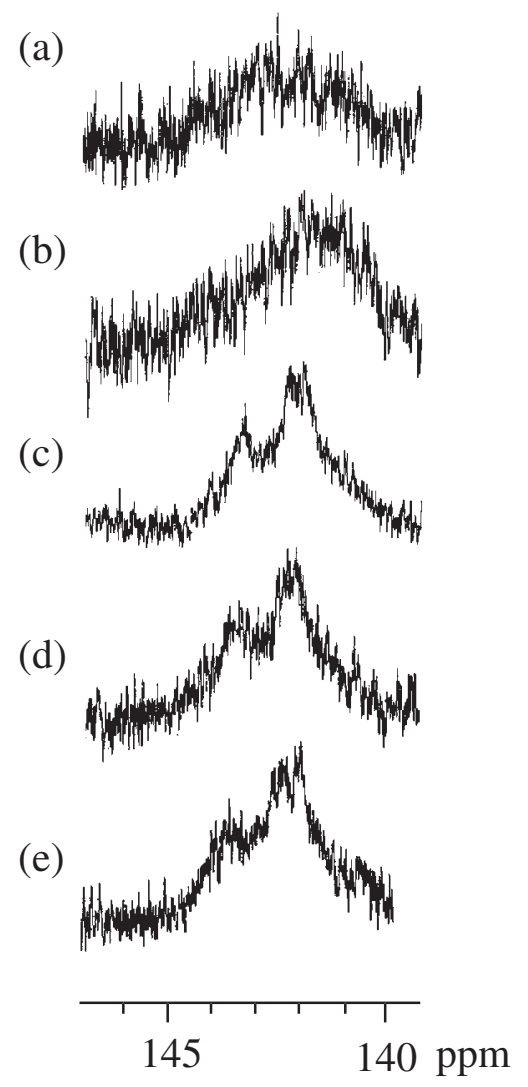

Figure 3. ${ }^{13} \mathrm{C}$ NMR spectra of the $\mathrm{C}-1$ (phenyl) carbon of poly(4)s obtained with $n$-BuLi (a), with $n$-BuLi-(-)-DDB (b), with $n$-BuLi-(-)-Sp (c), poly(5) obtained with $n$-BuLi-(-)-Sp (d), and poly(6) obained with $n$-BuLi-(-)-Sp (e) (in $\mathrm{CDCl}_{3}$ at $60{ }^{\circ} \mathrm{C}, 125 \mathrm{MHz}$ ).

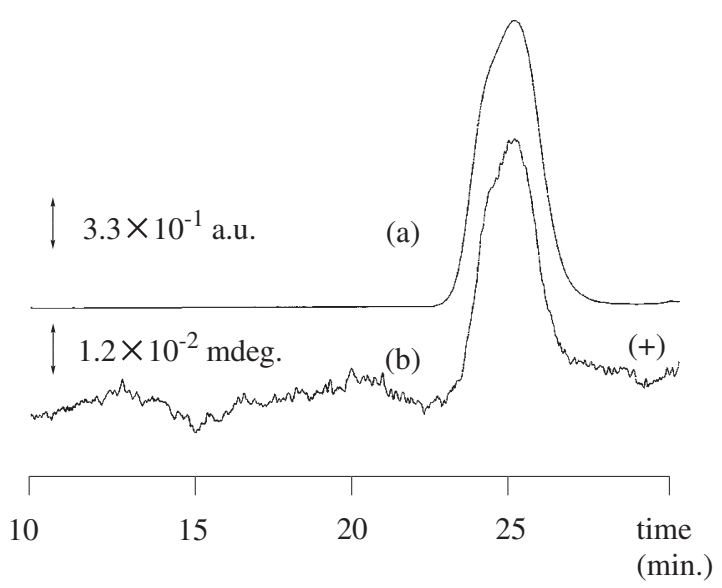

Figure 4. SEC traces of poly(5) obtained with $n$-BuLi-(-)-Sp at $0{ }^{\circ} \mathrm{C}$, monitored by $\mathrm{UV}$ (a) and by polarimetric (b) detectors (A series of SEC columns, Shodex KF-803, KF-806L, and Tosoh TSKgel G2000H $\mathrm{HL}_{\mathrm{L}}$, was used).

the polarimeteric detection is almost coincident with that monitored by UV. The SEC analyses for the optically active poly(4) and poly(6) also showed similar results. These suggest that the anionically prepared poly(4)-poly(6) with $n$-BuLi-(-)-Sp may have a stable chiral conformation, probably a helical conforma-

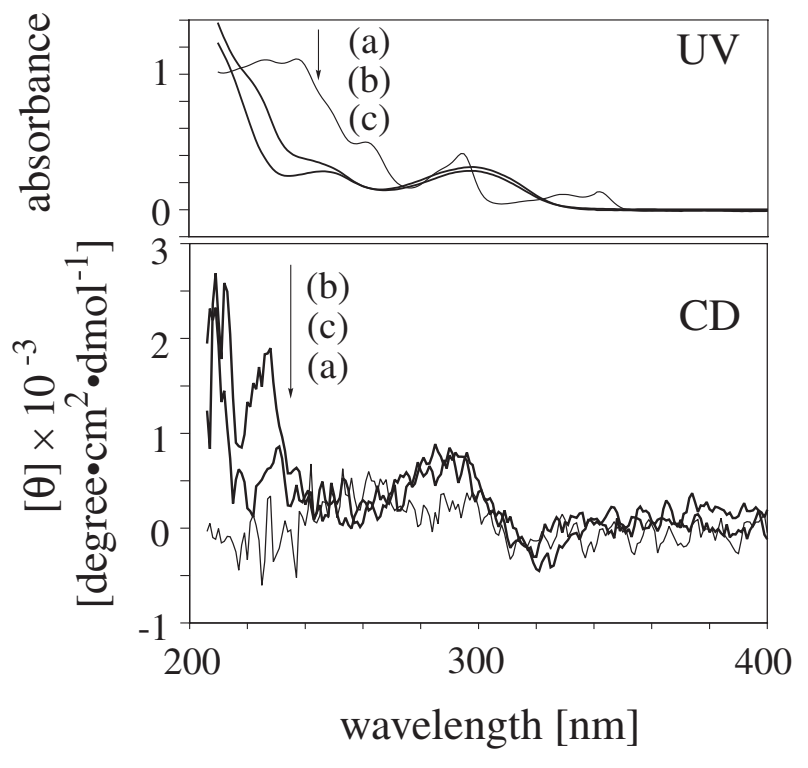

Figure 5. UV and CD spectra of poly(3) (a), poly(5) (b), and poly(6) (c), obained with $n$-BuLi-(-)-Sp (in THF).

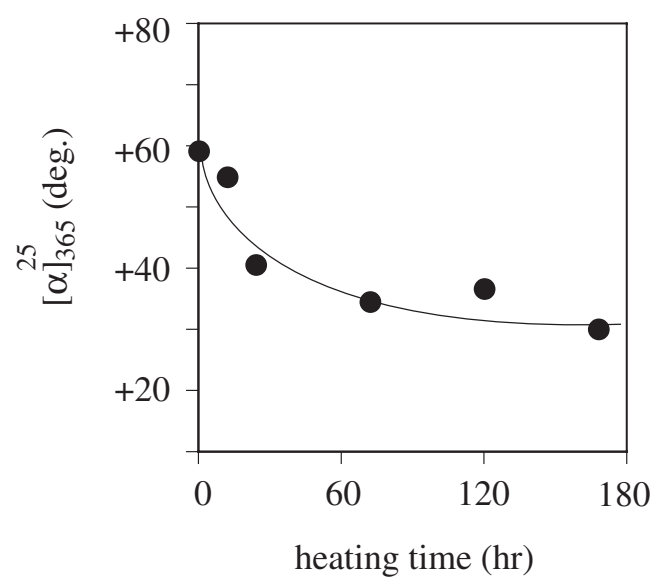

Figure 6. The polts of specific rotations of poly(5) during the heating in toluene at $100^{\circ} \mathrm{C}$.

tion, based on the stereoregular backbone structure.

Figure 5 shows the CD spectra in THF of the polymers obtained from 5 and $\mathbf{6}$ with (-)-Sp (Table II, entries 15 and 18). A weak cotton effect was observed around $290 \mathrm{~nm}$ for these polymers, while no significant absorption was observed for poly $(3)$ prepared with (-)-Sp.

The changes of the specific rotation during the heating of poly $(\mathbf{5})$ (Table II, entry 15$)$ in toluene at $100^{\circ} \mathrm{C}$ are plotted in Figure 6. For the first $20 \mathrm{~h}$, the specific rotation rapidly decreased and the $[\alpha]^{25}{ }_{365}$ value changed from $+59^{\circ}$ to $+30^{\circ}$ (in toluene) after about $70 \mathrm{~h}$, and the recovered polymer after $168 \mathrm{~h}$ showed a specific rotation, $[\alpha]^{25}{ }_{365}+28^{\circ}$ (in $\mathrm{CHCl}_{3}$ ) and molecular weight, $M_{\mathrm{n}}=2800$. These results imply that the higher order structure of poly $(\mathbf{5})$ formed during the asymmetric anionic polymerization was partially lost by heating. 


\section{CONCLUSIONS}

Novel styrene derivatives bearing bulky amino groups at ortho-position, such as $\mathbf{4 , 5}$, and $\mathbf{6}$ were synthesized, and the bulkiness of the ortho-substituents of these monomers significantly influenced the polymerizabilities and the stereostructure of the polymers. The asymmetric anionic polymerization with $n$-BuLi-(-)Sp afforded optically active polymers, whose chirality may be due to a chiral conformation, probably a helical structure, based on the stereoregular main chain structure.

Acknowledgment. H. Ajiro acknowledges the support of a Grant-in-Aid for Japan Society for the Promotion of Science (JSPS) Fellows (00770) from the Japan Ministry of Education, Culture, Sports, Science, and Technology.

\section{REFERENCES}

1. a) A. Hirao, M. Hayashi, and N. Haraguchi, Macromol. Symp., 183, 11 (2002).

b) A. Hirao, M. Hayashi, and S. Loykulnant, Macromol.
Symp., 161, 45 (2000).

c) S. Nakahama and A. Hirao, Prog. Polym. Sci., 15, 299 (1990).

2. a) G. Natta, P. Pino, P. Corradini, F. Danusso, and E. Mantica, J. Am. Chem. Soc., 77, 1700 (1955).

b) G. Natta, F. Danusso, and D. Sianesi, Makromol. Chem., 28, 253 (1958).

3. J. Geerts, M. V. Beylen, and G. Smets, J. Polym. Sci., Polym. Chem., 7, 2859 (1969).

4. H. Yuki, Y. Okamoto, Y. Kuwae, and K. Hatada, J. Polym. Sci., Polym. Chem., 7, 1933 (1969).

5. a) Y. Okamoto, K. Suzuki, K. Ohta, K. Hatada, and H. Yuki, J. Am. Chem. Soc., 101, 4763 (1979).

b) T. Nakano and Y. Okamoto, Chem. Rev., 101, 4013 (2001).

6. L. J. Ortiz and I. M. Khan, Macromolecules, 31, 5927 (1998).

7. a) S. Habaue, H. Ajiro, and Y. Okamoto, J. Polym. Sci., Part A: Polym. Chem., 38, 4088 (2000).

b) H. Ajiro, S. Habaue, and Y. Okamoto, Polym. J., 34, 57 (2002).

8. For example, see: a) T. Kawamura, T. Uryu, and K. Matsuzaki, Makromol. Chem., 183, 125 (1982).

b) N. Ishihara, T. Seimiya, M. Kuramoto, and M. Uoi, Macromolecules, 19, 2464 (1986).

c) T. Makino and T. E. Hogen-Esch, Macromolecules, 32, 5712 (1999). 